\title{
CRC forced to compromise over tobacco funding ban
}

After 15 months of wrangling, the Cancer Research Campaign (CRC) has reached agreement with British universities on a policy that it hopes will prevent tobacco companies from funding medical and scientific research in the UK. The policy, which comes into force on April 6th, rules out CRC funding for scientists who work in close proximity to, or share equipment with, those who are funded by the tobacco industry. However, the ban does not extend to research carried out in separate departments within the same university-a distinct climb down of the CRC's original goal.

Initially, the CRC had wanted to go much further even than safeguarding the independence of medical research: it had wanted to stop companies from buying prestige and respectability through funding any area of academic research. But a blanket ban faltered after a public showdown in which the CRC threatened to withdraw $£ 2$ million in grants from Cambridge University, which accepted $£ 1.5$ million from British American Tobacco (BAT) to establish a chair for International Relations. Cambridge stood its ground, which forced a meeting between the CRC and the committee of University Vice Chancellors to thrash out an agreement.

The protocol defines tobacco funding as any support that carries the trade name of the tobacco company. "Respectability by association is what it's all about. If [tobacco funding] had to be anonymous it would soon dry up," director general of the CRC Gordon McVie told Nature Medicine.

Graham Zellick, vice-chancellor of the University of London and a lawyer who was involved in negotiating the policy on behalf of the universities, said the CRC's threat was probably illegal. Universities are charities-a status that restricts their political activity-and a refusal to accept any funds from the tobacco industry could be interpreted as a political act. McVie now accepts that the wide-ranging threat was itself unethical in its attempt to dictate policy across the entire spectrum of research. The CRC hopes that the less draconian rules could achieve its wider aims by forcing other departments to look at their own ethical policies.

By agreeing to the code, universities have avoided losing up to a fifth of their total income, which comes from medical charities. At around $£ 55$ million a year, the CRC provides around one-third of all cancer funds and provides four times as much funding for cancer research as does the UK government, which spends $£ 14$ million on oncology research through the Medical Research Council (MRC). And although a survey of 185,000 biomedical papers published between 1994 and 1998 by the Wellcome Trust found that Glasgow was the only medical school not to receive funds from tobacco companies, the $£ 19$ million tobacco money provided over the four year period pales by comparison with the $£ 340$ million a year given by UK medical research charities.

Imperial Tobacco and RJ Reynolds told Nature Medicine that they do not fund medical research directly in the UK. Rothmans and Gallaher refused to comment on the issue. BAT admits spending $£ 1$ million a year on health research in the UK, and says that as a result of the new policy it will simply move this to Europe, where

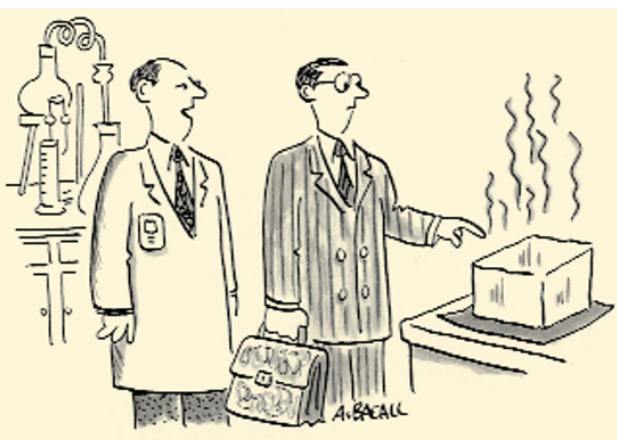

"Yes, the dry ice is smoking, but I can assure you it is not funded by the tobacco industry."

universities and charities are more relaxed in their approach to smoking.

The Wellcome Trust, which spends $£ 250$ million a year on research, already operates a mutually exclusive policy for researchers receiving tobacco money and aims to increase prominence of this clause in the forthcoming reprint of its grant conditions. The Imperial Cancer Research Fund (ICRF), which spends $£ 56$ million on research largely within its own institutes, also supports the policy. ICRF collaborative work with the University of London only got the go-ahead after tobacco funding was discontinued at the university's Health Behaviour unit.

However, the MRC has become increasingly isolated on the issue and refuses to sign up to the CRC code. "We make our decisions on a case-by-case basis," insists an MRC spokesperson. In fact, in November 1996 the MRC dismissed its head of communications, Mary Rice, after she criticized a decision to solicit $£ 147,000$ from BAT for an investigation into the effects of nicotine in Alzheimer Disease. Jim

Edwardson, director of neurology at the MRC unit that took BAT's money, said he would not do so again because of the bad publicity associated with the deal.

But the new policy will be hard to police. There is no central registration of university funding and only one in ten universities has an ethics committee to examine funding sources. Tobacco company annual reports provide little information on benefactors.

Zellick argues that it is not the job of universities to police the new agreement and McVie hopes that the International Agency on Tobacco and Health, an anti-smoking organization, will be responsible for monitoring the situation. Ultimately, the CRC will probably have to rely on trust and a growing sense that tobacco money is not acceptable.

DAVID FIRN, LONDON

\section{NIH opens conflict-of-interest investigation}

Harold Varmus, director of the US National Institutes of Health (NIH), has called for an internal inquiry into the financial relationship between one of NIH's leading diabetes researchers and the manufacturer of a diabetes drug that has been linked to nearly three dozen deaths since it came onto the US market in early 1997. The inquiry coincides with a series of detailed questions sent to Varmus from Congressman Henry Waxman (D-Ca), which elicited a four-page response from Varmus expressing NIH's deep concern "about public reaction to a possible conflict of interest."

Varmus has asked the Inspector General of the Department of Health and Human Services to determine whether Richard Eastman, a researcher at the National Institute of Diabetes and Digestive and Kidney Diseases, violated any laws. Eastman accepted consulting fees from the New Jersey based pharmaceutical com- 